\title{
Effect of Hand Grips and a Labile Surface on Upper Extremity Muscle Activities during Push-up Exercise on a Multi-Function Balance Board
}

\author{
Se-Yeon Park ${ }^{1)}$, Hun Kwon ${ }^{2)}$, Dong-hyun Kim²), Sung-won Jeon ${ }^{2)}$, Lee-Ji Lim ${ }^{2)}$, \\ Si-eun Lee ${ }^{2)}$, Mi-Jin Park ${ }^{2)}$, Ji-hyuk Park ${ }^{3)}$, Won-Gyu Yoo ${ }^{4)}$ \\ 1) Department of Physical Therapy, The Graduate School, Inje University \\ 2) Department of Physical Therapy, The Undergraduate School, Inje University \\ 3) Department of Occupational Therapy, College of Health Science, Yonsei University \\ 4) Department of Physical Therapy, College of Biomedical Science and Engineering, Inje University \\ and Elderly Life Redesign Institute: 607 Obangdong, Gimhae, Gyeongsangnam-do 621-749, Republic \\ of Korea. TEL: +82 55-320-3994, FAX: +82 55-329-1678, E-mail:won7y@inje.ac.kr
}

\begin{abstract}
Purpose] The aim of this study was to reveal the effect of using hand-grips and a labile surface during push-up exercise. [Subjects] We recruited 12 male subjects. [Methods] Push-up exercises were performed under four different conditions on a multi-function balance board: a stable surface with and without hand-grips, a labile surface with and without hand-grips. Muscle activities of the upper trapezius (UT), serratus anterior (SA), extensor carpi radialis (ECR), and flexor carpi ulnaris(FCU) muscles were recorded. [Results] Push-ups on the labile surface tended to increase greater activation of the SA, and significantly increased both UT and FCU activities compared with the same exercise on the stable surface regardless of hand-grip usage. Push-ups on the labile surface with hand-grips condition caused significantly increased in ECR activation compared to other conditions. [Conclusion] Usage of hand-grips is recommended when push-ups are performed on a labile surface to reduce muscular imbalance in the wrist.

Key words: Electromyography, Hand-grips, Support surfaces
\end{abstract}

(This article was submitted Sep. 13, 2012, and was accepted Oct. 19, 2012)

\section{INTRODUCTION}

Previous studies have described the muscular activation that occurs during a conventional push-up. A low speed and a narrow-base for a push up have been suggested to improve the efficiency of muscle training ${ }^{1,2)}$. Recent studies on the effects of a labile surface and the use of hand-grips on muscular activation during push-up exercise ${ }^{3-6)}$ have reported higher activation of the upper trapezius (UT) during push-ups on a labile surface ${ }^{3,7)}$. Although hand-grips are in general use for push-ups, the effects of hand-grip use on muscle activation have rarely been reported. In addition, no study has focused on the forearm muscles, which are directly influenced by hand position. The wrist is a flexible joint ${ }^{8)}$, which suggests that use of a hand-grip could change the forearm muscular activity, especially when the exercise is performed on a labile surface. In order to compare push-ups performed on stable and unstable surfaces, with and without hand-grips, we devised a multi-function balance board (MFB) with detachable hand-grips that can provide information about balance. The purpose of present study was to use this MFB to investigate the effects of using hand-grips and a labile surface during push-ups.

\section{SUBJECTS AND METHODS}

The subjects were 12 males aged $23.7 \pm 2.3$ years (mean $\pm \mathrm{SD}$ ), whose average height was $175.3 \pm 3.8 \mathrm{~cm}$, and average body weight was $67.4 \pm 6.9 \mathrm{~kg}$. None of the subjects had any musculoskeletal disorder or pain in the upper extremities. Activations of the serratus anterior (SA), upper trapezius (UT), extensor carpi radialis (ECR), and flexor carpi ulnaris (FCU) muscles were recorded by electromyography (EMG) (Delsys, Boston, MA, USA). The EMG signals were sampled at $2000 \mathrm{~Hz}$, with band pass filtering between 20 and $450 \mathrm{~Hz}$. Six Trigno electrodes were attached to right dominant side of each subject ${ }^{9)}$. Four push-up conditions were examined in the present study: push-ups on a stable surface (PS); push-ups performed with hand-grips on a stable surface (PHS); push-ups on a labile surface (PL); and push-ups performed with hand-grips on a labile surface (PHL). A newly designed MFB, which incorporates detachable hand-grips and labile support, was used and a digital level gauge provided visual feedback of horizontality. The degree of horizontality was presented as a \% of horizontality with respect to the initial calibration. Each subject was asked to perform a descending push-up in two seconds, until they touched a cup marker placed on the surface, and then to ascend in two seconds. The speed was regulated with a metronome. The maximal voluntary contraction (MVC) of 
Table 1 . Normalized EMG data for UT, SA, ECR and FCU under the different push-up conditions

\begin{tabular}{lcccc}
\hline \multirow{2}{*}{$\begin{array}{l}\text { Mean } \pm \text { SD } \\
(\% M V C)\end{array}$} & \multicolumn{2}{c}{ Push-up without hand-grip } & \multicolumn{2}{c}{ Push-up with hand-grip } \\
\cline { 2 - 5 } & Stable surface & Labile surface & Stable surface & Labile surface \\
\hline UT & $11.48 \pm 7.34$ & $25.06 \pm 12.32^{*}$ & $13.85 \pm 8.89$ & $26.16 \pm 16.16^{*}$ \\
SA & $27.28 \pm 8.67$ & $34.48 \pm 12.62^{*}$ & $23.39 \pm 7.19$ & $28.49 \pm 9.49$ \\
ECR & $8.51 \pm 6.48$ & $10.98 \pm 8.16$ & $8.56 \pm 3.51$ & $21.33 \pm 7.21^{*}$ \\
FCU & $23.21 \pm 16.89$ & $51.11 \pm 24.53^{*}$ & $22.93 \pm 9.11$ & $44.3 \pm 13.92^{*}$ \\
\hline
\end{tabular}

each muscle was measured to normalize the EMG signal ${ }^{9)}$. One-way repeated-measures ANOVA was conducted to test for differences in each muscle's \%MVC among the conditions using the SPSS statistical package (version 18.0; SPSS, Chicago, IL, USA). Significant main differences were determined using the Bonferroni correction. Significance was accepted for values of $\mathrm{p}<0.05$.

\section{RESULTS}

The \%MVC of the SA differed significantly among the conditions. The PL condition showed caused significantly increased SA activation compared with the PS and PHS conditions $(p<0.05)$. Significant differences were seen in the \%MVC values of UT, ECR, and FCU. The PL and PHL conditions significantly increased UT and FCU compared to the PS and PHS conditions, regardless of the use of handgrips $(p<0.05)$. The \%MVC of the ECR under the PHL condition was significantly higher than that of the other PS, PL, and PHS conditions $(\mathrm{p}<0.05)$ (Table 1$)$.

\section{DISCUSSION}

This study examined 4 categories of muscular demand: low (20\% MVC), moderate (20-40\%), high (41-60\%), and very high $(61 \% \sim)^{10)}$. The push-up used in the present study moderately strengthens SA and FCU. To activate both UT and SA at a moderate level, the use of a labile surface is recommended. However, previous findings agreed that minimizing the activity of the upper trapezius and activating the serratus anterior, helps to regain glenohumeral rhythm ${ }^{10,11)}$. Therefore, push-ups on a labile surface should be carefully performed by patients with shoulder disorders. A significant increase was observed in the UT, SA, and FCU under the labile surface conditions. A previous study that used a balance board reported UT results that were similar to those of the present study ${ }^{3}$. Under the PHL and PL conditions, balance was maintained by watching the level gauge on the MFB. The proximal musculature that attaches to the scapulae may be more activated in order to maintain the scapular position ${ }^{12}$. Although we did not measure the kinematics of the wrist, the higher activation of FCU observed under the PL and PHL conditions might have been due to increased ulnar deviation. The hand position may influence shoulder muscle activation during a push-up ${ }^{2,5)}$. Rotatable hand-grips have been reported not to enhance scapulothoracic muscular recruitment ${ }^{5)}$, similar to what we found in the present study. The use of hand-grips appeared to require less anterior-posterior and medio-lateral force than palm or fist push-ups Our opinion is that, under the PHL condition, the ECR counteracts the FCU activation, which contributes to maintenance of the neutral position of the wrist joint by grasping the hand-grip ${ }^{8}$.

\section{ACKNOWLEDGEMENTS}

This work was supported by a Korea Foundation for the Advancement of Science \& Creativity (KOFAC) grant funded by the Korean Government (MEST).

\section{REFERENCES}

1) Chou PH, Chou YL, Kuo CM, et al.: Analysis for different push-up speed on joint loading of the upper extremity. National Science Council Annual Report, 2002, NSC91-2320-B-037-017.

2) Cogley RM, Archambault TA, Fibeger JF, et al.: Comparison of muscle activation using various hand positions during the push-up exercise. J Strength Cond Res, 2005, 19: 628-633. [Medline]

3) Tucker WS, Armstrong CW, Gribble PA, et al.: Scapular muscle activity in overhead athletes with symptoms of secondary shoulder impingement during closed chain exercises. Arch Phys Med Rehabil, 2010, 91: 550-556. [Medline] [CrossRef]

4) Lehman GJ, Gilas D, Patel U: An unstable support surface does not increase scapulothoracic stabilizing muscle activity during push-up and push-up plus exercises. Man Ther, 2008, 13: 500-506. [Medline] [CrossRef]

5) Youdas JW, Budach BD, Ellerbusch JV, et al.: Comparison of muscleactivation patterns during the conventional push-up and perfect $\bullet$ pushup $^{\mathrm{TM}}$ exercises. J Strength Cond Res, 2010, 24: 3352-3362. [Medline] [CrossRef]

6) Freeman S, Karpowicz A, Gray J, et al.: Quantifying muscle patterns and spine load during various forms of the push-up. Med Sci Sports Exerc, 2006, 38: 570-577. [Medline] [CrossRef]

7) Hatzitaki V, Amiridis IG, Nikodelis T, et al.: Direction-induced effects of visually guided weight-shifting training on standing balance in the elderly. Gerontology, 2009, 55: 145-152. [Medline] [CrossRef]

8) Neumann DA: Kinesiology of the musculoskeletal system: foundations for physical rehabilitation. St Louis: Mosby, 2002.

9) Cram JR, Kasman GS, Holtz J: Introduction to surface electromyography. Maryland: Aspen, 1998

10) Digiovine NM, Jobe FW, Pink M, et al.: An electromyographic analysis of the upper extremity in pitching. J Shoulder Elbow Surg, 1992, 1: 15-25. [Medline] [CrossRef]

11) Ludewig PM, Hoff MS, Osowski EE, et al: Relative balance of serratus anterior and upper trapezius muscle activity during push-up exercises. Am J Sports Med, 2004, 32: 484-493. [Medline] [CrossRef]

12) Kibler WB: The role of the scapula in athletic shoulder function. Am J Sports Med, 1998, 26: 325-337. [Medline] 